\title{
The effect of Cognitive Behavior Therapy (CBT) and Rational Emotive Behavior Therapy (REBT) to the loneliness elderly
}

\author{
$1^{\text {st }}$ Anny Rosiana \\ Universitas Muhammadiyah Kudus \\ Indonesia \\ annyrosiana@umkudus.ac.id
}

\author{
$2^{\text {nd }}$ Puji Krisbiyantoro \\ Universitas Muhammadiyah Kudus \\ Indonesia
}

\author{
$3^{\text {rd }}$ Ali Solikin \\ Universitas Muhammadiyah Kudus \\ Indonesia
}

\begin{abstract}
There are 450 million people in the world that have metal disorder (WHO, 2017). The purpose of this study is to describe the effect of CBT and REBT to solve the loneliness in the elderly. The method of this research is quasi experimental pre-post test with control group.. The sample used is purposive sampling technique with 60 respondents that divided 30 interventions and 30 controls. The results found a decrease in symptoms and an increase in the ability of PK and HDR clients who get CBT and REBT greater than those who do not get CBT and REBT (p-value $<0.05$ ). The CBT and REBT technique is recommended used by the specialist therapies in addition to generalist therapy.
\end{abstract}

Keywords-Effect, Cognitive, Behavior, Therapy, CBT, Emotive

\section{INTRODUCTION}

Elderly according to the World Health Organization is the age group of residents aged 60 years and over. In Indonesia, the elderly are placed in an honorable position, so that the elderly in the community continue to show their attention and participation in community matters. From the point of view of Indonesia's socio-cultural tradition, the elderly are the responsibility of the child and live in the child's home. Caring for parents is one form of devotion to children who have been caring for and raising them. The elderly who have a family within the eastern culture are still very fortunate, because family members will continue to care for the elderly with patience and sacrifice [1].

Changes experienced by the elderly start from changes in physical function and are vulnerable due to decreased biological and physical function, which ultimately results in decreased work production. Changes from the Psychological aspect of the elderly require closer intimacy with all family members and a desire to share fun with the family. Gathering with family becomes the desire of the elderly because there is plenty of free time, in contrast to adult time where more activities outside the home. The desire to always be close to the family, feel part of the family and uninterrupted contact with children, as well as their friends, needs attention. One social interaction that is still expected by the elderly from his family is the attention, assistance and deep relationships[2].

Changes in psychological aspects are becoming increasingly important in the lives of the elderly because the elderly must face the community's perception of the elderly that as the elderly will become senile as a result of cognitive impairment they experience. inadequate social support received by the elderly can cause psychosocial disorders such as feelings of loss, loneliness, depression, difficulty sleeping[3].

Loneliness is an exaggerated unpleasant feeling and this is related to the inadequate human need for Interpersonal Intimacy. Loneliness is defined as the dissatisfaction of social relationships and close relationships less than expected. Loneliness is usually experienced by the elderly when the death of a spouse / close friend, especially if he himself is also experiencing a variety of severe physical illness, mobility disorders or sensory impairments, especially hearing loss [4] Loneliness is not just the absence of other people around us, because someone in social interaction also requires a close relationship and not just an official relationship, shallow and lip service, but a deep relationship.

Actually this loneliness can be overcome so that it does not lead to depressive behavior by facilitating a relationship that uses empathetic communication so that it creates a satisfaction in building a relationship and the elderly will feel safe to start a relationship. Given the serious impact of this lonely problem it is necessary to pay attention to the nurse as someone who plays a role in caring for or maintaining, helping and protecting someone due to illness, injury and the aging process[5]

One effort to deal with loneliness is to use several techniques, including social skills training (SST), Cognitive-Behavioral Therapy, shyness Groups [6]. Cognitive behavioral therapy and rational emotive behavior therapy which are carried out separately are proven to help clients who experience mental disorders, especially loneliness. Cognitive behavioral therapy and Rational 
emotive behavior therapy enhance the cognitive and adaptive behavior of clients who feel lonely Therefore, the writer would like to know the effectiveness of the effects of Cognitive Behavior Therapy (CBT) and Rational Emotive Behavior Therapy (REBT) to the loneliness of the elderly.

\section{METHOD OF THE RESEARCH}

Quasi Experimental Pre-Post Test with "Control Group" with the intervention of Cognitive Behavior Tharapy (CBT) and Rational Emotive Behavior Therapy (REBT). Research conducted on clients' violent behavior and low self-esteem were carried out before and after CBT and REBT therapy. This study compares the differences between two groups of clients with violent behavior and low self-esteem, namely the intervention group (the group that gets CBT and REBT) and the control group (the group that does not get CBT and REBT). Inpatient room of Marzoeki Mahdi Hospital, Bogor. The population and sample were 60 respondents, 30 for the control group and 30 respondents for the intervention group. Sampling technique uses total sampling.

\section{FINDING AND DISCUSSION}

In this research, the writer analyzed the effectiveness of Cognitive Behavior Therapy (CBT) and Rational Emotive Behavior Therapy (REBT) for the loneliness elderly. The social signs and symptoms explored in this study are changes in the pattern of client interactions with others in a state of anger or reticence. Speech patterns: tone of speech, speed of speech, the desire to talk with others. When angry, most clients speak in a high voice, speak faster and refuse to be invited to talk. Or they even tend to be quiet, and do not want to socialize. In this study social signs and symptoms experienced a greater decline compared to other symptoms. This occurred because CBT and REBT caused changes in judgment and confidence in events both because other people, the environment and oneself that were negative only based on their own opinions became positive based on facts. Positive thoughts and beliefs cause the client not to limit himself in dealing with others.

TABLE I. CHANGES IN SYMPTOMS BEFORE AND AFTER CBT AND REBT IN THE INTERVENTION AND CONTROL GROUP (N = 60)

\begin{tabular}{|c|c|c|c|c|c|c|}
\hline $\begin{array}{l}\text { Signs } \\
\text { Behavioral } \\
\text { Symptoms }\end{array}$ & Group & $\begin{array}{l}\text { Mean } \\
\text { Pretest }\end{array}$ & $\begin{array}{l}\text { Mean } \\
\text { posttest }\end{array}$ & $\begin{array}{l}\text { Mean } \\
\text { differences }\end{array}$ & $\begin{array}{l}\text { SD } \\
\text { Difference }\end{array}$ & p Value \\
\hline Cognitive & $\begin{array}{l}\text { Experimental } \\
\text { Control }\end{array}$ & $\begin{array}{l}14,23 \\
15,60\end{array}$ & $\begin{array}{l}7,13 \\
12,03\end{array}$ & $\begin{array}{l}7,10 \\
3,57\end{array}$ & $\begin{array}{l}3,089 \\
2,029\end{array}$ & $\begin{array}{l}0,000 \\
0,002\end{array}$ \\
\hline Emotion & $\begin{array}{l}\text { Experimental } \\
\text { Control }\end{array}$ & $\begin{array}{l}17,07 \\
16,53\end{array}$ & $\begin{array}{l}8,07 \\
13,23\end{array}$ & $\begin{array}{l}9,00 \\
3,30\end{array}$ & $\begin{array}{l}3,639 \\
2,380\end{array}$ & $\begin{array}{l}0,000 \\
0,000\end{array}$ \\
\hline Behaviour & $\begin{array}{l}\text { Experimental } \\
\text { Control }\end{array}$ & $\begin{array}{l}13,73 \\
15,20\end{array}$ & $\begin{array}{l}7,27 \\
12,07\end{array}$ & $\begin{array}{l}6,47 \\
3,13\end{array}$ & $\begin{array}{l}3,148 \\
2,417\end{array}$ & $\begin{array}{l}0,000 \\
0,000\end{array}$ \\
\hline Social & $\begin{array}{l}\text { Experimental } \\
\text { Control }\end{array}$ & $\begin{array}{l}18,77 \\
17,27\end{array}$ & $\begin{array}{l}8,17 \\
13,57\end{array}$ & $\begin{array}{l}10,60 \\
3,70\end{array}$ & $\begin{array}{l}3,201 \\
2,395\end{array}$ & $\begin{array}{l}0,000 \\
0,000\end{array}$ \\
\hline Physiology & $\begin{array}{l}\text { Experimental } \\
\text { Control }\end{array}$ & $\begin{array}{l}8,87 \\
7,20\end{array}$ & $\begin{array}{l}5,33 \\
7,43\end{array}$ & $\begin{array}{l}3,33 \\
0,23\end{array}$ & $\begin{array}{l}1,008 \\
1,040\end{array}$ & $\begin{array}{l}0,000 \\
0,100\end{array}$ \\
\hline Composit & $\begin{array}{l}\text { Experimental } \\
\text { Control }\end{array}$ & $\begin{array}{l}72,67 \\
71,80\end{array}$ & $\begin{array}{l}35,70 \\
58,33\end{array}$ & $\begin{array}{l}36,97 \\
13,47\end{array}$ & $\begin{array}{l}8,032 \\
6,421\end{array}$ & $\begin{array}{l}0,000 \\
0,000\end{array}$ \\
\hline
\end{tabular}

The provision of REBT to the client causes the client to learn to think rationally, to control his feelings and behavior, this ability will cause his client's feelings to become calm and reduced stress stimulus to the nervous system, especially the limbic system and neurotransmitters and hormonal systems where an increase in ACTH does not occur and decreased glucocorticoid production of metabolic formation energy and increased nerve function also decrease because epineprin and norepineprin as neurotransmitters increase impulse transfer and increase the sympathetic system decreases so that the client's physiological response to stress will decrease the client becomes more able to control himself and his physiological response decreases.

Previous studies are consistent with the results of research conducted by researchers in which CBT and REBT can reduce behavioral symptoms that are very meaningful. The difference in research conducted by researchers with previous research is that researchers use two specialist therapies simultaneously to clients who have a diagnosis of violent behavior and low self-esteem (more than one diagnosis).

Combining CBT and REBT therapy will further enhance the effectiveness of the results of specialist therapy, because CBT tries to identify and change "distortions" or "unrealistic" ways of thinking and ultimately affect emotions and behavior, while REBT provides opportunities for clients to recognize feelings caused by irrational thoughts about every event or event that makes the client behave violently so that the client recognizes feelings that can lead to maladaptive behavior, REBT is a method for understanding and overcoming emotional and behavioral problems. Behavior is the result of thoughts and feelings in the client. If thoughts (cognitive) and feelings (emotions) can be controlled properly, client behavior will be more positive.

Therapy that is combined between CBT and REBT has the aim to complement each other where CBT which aims to improve cognitive abilities and behaviors will be strengthened with REBT which aims to improve the ability 
to think rationally so that clients are able to control their emotions / feelings and behavior. The emotions and behavior are the result of thought processes that make it possible for humans to modify it to achieve different ways of feeling and acting.

Therapy that researchers do to clients begins with the client guided to reveal events that cause disturbed thoughts and feelings / emotions so as to conduct violent behavior. Then the client is invited to gauge the feelings that arise and assess the cause of the emergence of feelings whether due to rational beliefs or not. If due to irrational beliefs, the client is helped to change his mind to be rational so that his emotions become better and the drive to commit violent behavior is reduced.

In addition to assessing client incidents, they are also invited to assess themselves, to find out whether there is a cognitive distortion that causes self-assessment to be negative, because negative judgments will cause negative behavior, one of which is violence. If negative thoughts and behaviors are found, the client is invited to fight these thoughts and control their behavior better.

\section{CONCLUSION}

Based on this research, Cognitive Behavior Therapy and Rational Emotive Behavior Therapy have a significant influence on the attitudes of elderly people who experience loneliness. The provision of specialist therapies combined between CBT and REBT provides higher effectiveness when compared to only one therapy. CBT and REBT therapy on the client causes a difference in the increase in behavioral / psychomotor abilities 38.73 whereas with only CBT therapy causes a difference in the increase in cognitive abilities PK: 25.46 and HDR: 13.00.

\section{REFERENCES}

[1] A. H. Şar, G. Y. Göktürk, G. Tura, and N. Kazaz, "Is the Internet Use an Effective Method to Cope With Elderly Loneliness and Decrease Loneliness Symptom?," Procedia - Soc. Behav. Sci., vol. 55, pp. 1053-1059, 2012.

[2] S. N. Hosseininezhad, A. Ebrahimi, G. K. Hosain, D. Fathi, and S. M. M. Moosavi, "The Effectiveness of Cognitive-Behavioral Therapy on Bereaved University Students' Hope," Int. J. Med. Res. Heal. Sci., vol. 5, no. 5, S, SI, pp. 344-348, 2016.

[3] M. R.-V. Joan Domènech-Abella, Jordi Mundó, Josep Maria Haroac, "Anxiety, depression, loneliness and social network in the elderly: Longitudinal associations from The Irish Longitudinal Study on Ageing (TILDA) Author links open overlay panel," J. Affect. Disord., vol. 246, pp. 82-88, 2019.

[4] Y. S. Xia Zhaoa, Dan Zhanga, Menglian Wua, Yang Yanga, Hui Xiea, Yuqin Lib, Jihui Jiaa, "Loneliness and depression symptoms among the elderly in nursing homes: A moderated mediation model of resilience and social support," Psychiatry Res., 2018.

[5] F. K. Saleh Baberi and Z. D. Bozorgi, "Examining the Effectiveness of Social Skills Training on Loneliness and Achievement Motivation among Nurses," Rev. Eur. Stud., vol. 8, no. 4, p. 167, 2016.

[6] P. K. Rabia Hacihasanoğlu, Arzu Yildirim, "Loneliness in elderly individuals, level of dependence in activities of daily living (ADL) and influential factors," Arch. Gerontol. Geriatr. Vol. 54, Issue 1, January-February 2012, Pages 61-66, 2012. 